\title{
Representative Bureaucracy and Specialist Knowledge in the European Commission
}

\author{
Johan Christensen \\ Petra van den Bekerom \\ Joris van der Voet \\ Leiden University, Institute of Public Administration, The Netherlands
}

Corresponding author:

Johan Christensen

Institute of Public Administration

Turfmarkt 99

2511 DP The Hague

The Netherlands

Telephone: +31708009408

E-mail: j.christensen@fgga.leidenuniv.nl

Published as:

Christensen, J., Van den Bekerom, P., and Van der Voet, J. (2017). 'Representative Bureaucracy and Specialist Knowledge in the European Commission', Public Administration 95(2): 450-467. 


\begin{abstract}
The article addresses an issue that has received little attention in the literature on representative bureaucracy, namely the relationship between representativeness and specialized expertise in public administration. While representation may strengthen the legitimacy of public bureaucracies, what implications does it have for expert knowledge in these organizations? This issue is examined by looking at the recruitment of civil servants to the European Commission, an international bureaucracy where the question of geographical representation is of fundamental importance. Based on a quantitative analysis of nearly 200 recruitment competitions to the organization from 1958 to 2015, the article finds that competitions related to EU enlargement where nationality was an explicit criterion put significantly less emphasis on specialist qualifications and knowledge than other competitions. This indicates a negative relationship between geographical representation and specialized expertise in recruitment to the European Commission. Implications for broader debates about representative bureaucracy and international public administrations are discussed.
\end{abstract}




\section{INTRODUCTION}

The Weberian model of bureaucracy has traditionally underpinned the structure and management of most public administrations. A core element of the Weberian model is that officials possess specialized expertise, that is, technical knowledge acquired through formal training, which Weber saw as the principal reason for the superior efficiency of bureaucracy as an organizational form (Weber 1947, pp. 337, 339). Yet, in recent decades, the Weberian conception of bureaucracy has been challenged, inter alia by ideas about representative bureaucracy. The representative bureaucracy literature is concerned with the extent to which public organizations are representative of the society that they serve (Groeneveld and Van de Walle 2010; Andrews and Ashworth 2015). It highlights how a representative composition of staff in public organizations may contribute to increased legitimacy and organizational performance (Groeneveld et al. 2016). However, these arguments inevitably raise questions about the place of specialized knowledge within a representative bureaucracy. Is representativeness beneficial or detrimental to expert knowledge in public organizations? Surprisingly, this issue has received limited attention in the representative bureaucracy literature. The aim of this study is therefore to shed light on the relationship between representation and specialized expertise in public administration.

An interesting site for exploring this issue is international bureaucracies, the administrative bodies of international governmental organizations (Knill and Bauer 2016). Although there are few studies of international organizations in the representative bureaucracy literature (see Gravier 2013), geographical representation is of fundamental importance within international bureaucracies. To ensure fair representation of member states, international organizations typically integrate staff from a large number of countries in their administrative apparatus. Geographical representation may contribute to the legitimacy of these organizations, 
by ensuring equal access to administrative positions for citizens from all member states and by strengthening the identification of national elites with the organization. It may also contribute to organizational performance by allowing the organization to draw on the knowledge of officials about political, administrative and societal features at the national level. Arguments about bureaucratic representation are particularly relevant to the European Union (EU), given the strong role of the executive bureaucracy in the organization. The executive body of the EU - the European Commission - enjoys considerable political power, including a near-monopoly on proposing legislation. Critics argue that the power of the executive and the weakness of parliamentary control has given rise to a lack of democratic legitimacy in the EU (see Follesdal and Hix 2006 for a review). In this kind of political system, bureaucratic representation may constitute an important supplement to political representation in terms of legitimacy (cf. Groeneveld et al. 2016). A couple of recent studies have indeed pointed to a clear rationale of bureaucratic representation in the European Commission's policies for recruiting officials from new EU member states (Gravier 2008, 2013). Yet, we know little about what influence representativeness has had on other aspects of the European Commission bureaucracy, including the role of knowledge in the administration. How has the recurring need to integrate citizens from new member states affected the emphasis on specialized expertise in the Commission?

This article addresses this issue by looking at the relationship between geographical representation and specialist knowledge criteria in centralized recruitment competitions to the European Commission. In the European Commission, most permanent officials are recruited through large-scale, publically advertised competitions organized periodically in a variety of fields, in which candidates are assessed based on educational qualifications and/or tests of different types of knowledge and skills (see Christensen 2015). The article examines the relationship between geographical representativeness and specialized expertise by systematically 
comparing the emphasis on specialist qualifications and knowledge in two types of recruitment competitions: (1) competitions where nationality was an explicit criterion - that is, the 'special enlargement competitions' organized to recruit citizens from new member states - and (2) competitions that did not take nationality into account. The main objective of this analysis is to contribute to the representative bureaucracy literature by empirically assessing the relationship between representation and specialized knowledge in a public administration. The second aim is to add to existing work on representative bureaucracy in international organizations, in particular regarding the impact of geographical representation. The final objective is to contribute to the public administration literature about the EU by examining how a growing need for representation in the European Commission has affected its recruitment policies.

The study examines the following research question: What is the relationship between geographical representation and specialist qualifications in the centralized recruitment competitions of the European Commission between 1958 and 2015? The analysis is based on a new dataset of nearly 200 recruitment competitions for the European Commission over a period of more than 50 years. The analysis shows that special enlargement competitions where nationality was an explicit criterion were significantly less likely to take educational qualifications into account and put significantly less emphasis on specialist knowledge in recruitment tests. Moreover, it shows that these effects were partly mediated by the administrative grade for which new entrants were sought and the defined field of recruitment. The article thus finds a negative relationship between geographical representativeness and specialist expertise in the recruitment policies of the European Commission. It argues that this relationship can be attributed to the greater perceived need for socializing officials from new member states into the norms of the organization (see Ban 2013), which entailed a greater emphasis on the ability of staff to fit into the organization than on their expert knowledge. The 
article also discusses possible implications of these findings for other international bureaucracies and for the literature on representative bureaucracy. Moreover, it speculates whether there may be a link between the multinational character of the European Commission and the increasingly generalist character of its administration (see Wille 2013; Suvarierol et al. 2013; Christensen 2015).

The article proceeds as follows: In the next section, it contrasts the role of specialist knowledge in the Weberian and representative bureaucracy models, discusses geographical representation within the EU bureaucracy, and develops a theoretical framework and hypotheses about the relationship between representation and specialist knowledge in recruitment. It then explains the research design, including the process of data collection, measures and analytical strategy. This is followed by a presentation of the results. The article concludes with a discussion of the central findings, limitations, and theoretical and substantive implications of the study.

\section{THEORETICAL FRAMEWORK}

\section{Representative bureaucracy and specialist expertise}

In the traditional Weberian model of bureaucracy, specialist expertise constitutes one of the basic characteristics. The specialization of administrative functions that lies at the core of the Weberian model presupposes that officials have relevant specialized expertise to carry out their tasks. 'Office management, at least all specialized office management,' argued Weber, 'usually presupposes thorough and expert training' (Weber 1978, pp. 198, 200). In fact, Weber pointed to technical expertise as the principal reason for the superior efficiency of bureaucracy as compared to all other forms of organization: 'The primary source of the superiority of bureaucratic administration lies in the role of technical knowledge [...] Bureaucratic administration means 
fundamentally the exercise of control on the basis of knowledge' (Weber 1947, pp. 337, 339). Weber's conception of specialized expertise was based on his distinction between the 'cultivated man' and the 'specialist type of man' (see Weber 1978, pp. 423-26). Whereas the cultivated man has a general education meant to stimulate his cultural quality, the specialist has undergone rational and specialized expert training aimed at providing him with skills that are useful for administrative purposes. As such, the specialized expertise needed to work in the bureaucracy is directly linked to the possession of 'educational certificates' (Weber 1978, p. 200).

Yet, beyond the efficiency of bureaucratic organization, Weber was also concerned about the democratic implications of this system. He saw an ambivalent relationship between specialized expertise in the bureaucracy and democratic or representative concerns. On the one hand, selection on the basis of qualifications meant 'a 'selection' of those who qualify from all social strata rather than a rule by notables' (Weber 1978, p. 240). Indeed, it has been noted how the introduction of Weberian meritocratic bureaucracy from the $19^{\text {th }}$ century onwards made public employment more representative by opening the way for the middle classes (Groeneveld and Van de Walle 2010). On the other hand, Weber pointed out that recruitment based on educational qualifications could create a 'privileged caste' of officials and exclude lowereducated classes from the administration (Weber 1978, pp. 240-41). In other words, a bureaucracy made up of the higher educated might be efficient but not reflective of the population (Groeneveld and Van de Walle 2010, p. 255).

This concern with the representative character of the public service lies at the core of the literature on 'representative bureaucracy'. The basic tenet of this literature is that public bureaucracies are more than tools for efficient administration; they are also institutions that should be representative of the society that they serve, for instance in terms of nationality, language, race, class or gender. Indeed, in many polities, representation in the non-elected public 
service is as important as political representation in the legislature (Hood and Lodge 2006, p. 34). Representative bureaucracy arguments take several different forms (see Groeneveld and Van de Walle 2010 for a review). One is the long-standing interest in administrative representation as a tool for ensuring the authority and legitimacy of the state (Kingsley 1944; cf. Tilly 1975). This work emphasizes how ethnic, racial or language groups in society are granted access to the administrative apparatus in exchange for allegiance to the state (Hood and Lodge 2006, p. 13). The idea of bureaucratic representation as power-sharing is particularly relevant in polities with deep ethnic or racial cleavages, such as in a number of developing countries (Esman 1997). Second, bureaucratic representation has been seen as a mechanism to ensure equal opportunity (Groeneveld and Van de Walle 2010, p. 244). This view is rooted in the argument that bureaucrats often have considerable discretion when making decisions and that these choices depend on officials' social-demographic background (Lipsky 1980; Meier and Bohte 2001). Representation in the public service thus gives disadvantaged groups the opportunity to voice and advance their interests. This is closely linked to the idea of active representation, that is, that bureaucrats actively represent the interests of their social group when making decisions, rather than simply reflecting the social-demographic make-up of the population (passive representation) (Mosher 1968). But representation as equal opportunity also has a more material side, namely that disadvantaged groups get access to public sector jobs. In both regards, ensuring equal opportunity is crucial for the legitimacy and credibility of the public service with citizens (Krislov 1974). Finally, recent work about representative bureaucracy highlights how diversity can contribute to the performance of public organizations (e.g. Groeneveld et al. 2016), for instance by positively influencing the interaction between street-level bureaucrats and clients.

The representative bureaucracy literature thus advances an understanding of public bureaucracies that is distinct from the Weberian model. The 'representational' logic stands in 
contrast to the idea of relying on public servants with special expert competence - who are 'far from representative of the wider society' (Hood and Lodge 2006, p. 38). Yet, surprisingly, the relationship between representation and expert knowledge has received limited attention in existing studies of representative bureaucracy (see, e.g. Kennedy 2014). To be sure, some arguments from this and related literatures touch upon the issue. In the diversity management literature, some scholars point to a 'diversity-validity dilemma' in personnel selection: selection procedures that provide valid indicators of job performance tend to disadvantage racial and ethnical minorities and women, and conversely, selection based on diversity makes it difficult to identify the best qualified candidates (e.g. Pyburn et al. 2008). Though relevant, this argument pertains to how selection procedures affect the success rates of different categories of individuals and not to the impact of representativeness at the organizational level. Moreover, it does not speak specifically to how representation may affect specialized knowledge. Regarding the relationship between representation and education, Carnevale notes how the underrepresentation of minorities in the US federal government is greater in positions that require a higher degree of technical or educational qualifications, because ethnic minorities are underrepresented in higher education (Carnevale 1991). Meier and Hawes similarly point out that the merit-based recruitment system for the higher echelons of the French administration has produced a highly unrepresentative bureaucratic elite (Meier and Hawes 2009). However, they reject the argument that governments need to lower recruitment standards in order to achieve a more representative bureaucracy, claiming instead that recruitment systems rarely provide valid measures of merit and often are biased in terms of social and racial background. 'To the extent that representative bureaucracies can produce higher levels of overall benefits,' they argue, 'representative bureaucracies operationalize a more valid concept of merit than do more traditional procedures' (Meier and Hawes 2009, p. 276). Yet, this argument seems to obscure the underlying issue. 
While there may be different ideas about what constitutes 'merit' or 'competence' in bureaucracies, few would disagree that the specialized expertise of officials - defined through the possession of higher educational qualifications based on specialized training - constitutes one important aspect of an efficient public administration. In other words, while representativeness and specialized expertise both are important features of a bureaucracy that produces good decisions, it makes sense to keep the two dimensions analytically separate. This does not mean that representative bureaucracies cannot also have a high degree of specialized expertise. As this review of the existing literature has shown, the relationship between representation and specialized knowledge in bureaucracies may be either positive or negative. Before setting out our position in this debate, we discuss the role of representation in the executive bureaucracy of the EU.

\section{Representative bureaucracy in the European Commission}

The European Commission is the executive arm of the European Union, charged with initiating EU policies and promoting the European interest. The Commission is a supranational body, formally independent and organizationally separated from the Council of the European Union, which represents the EU member states. The Commission is headed by a college of politically appointed Commissioners, who are drawn from the member states but represent the European interest. The Commission has a highly developed permanent bureaucracy, which is divided into nearly forty departments ('directorates-general' or DGs). The Commission bureaucracy counts about 33.000 officials drawn from the 28 member states, of which nearly 12.000 are permanent 'AD' level staff, that is, administrators with policy tasks.

Most permanent Commission officials are recruited through centralized, open competitions for life-long careers within the administration, in accordance with the EU staff 
regulations. Recruitment competitions are organized periodically in a variety of fields and for different administrative grades and involve assessment on the basis of educational qualifications and/or oral, written or practical tests (see Christensen 2015). Traditionally, each of the major EU institutions was in charge of its own recruitment (Ban 2010). In the Commission, the responsibility for staffing lay with DG Personnel and Administration, which determined the competition schedule and the modalities of the selection procedure (Desbois 2003). In 2003, the responsibility for organizing recruitment competitions for the Commission and the other major European institutions was transferred to a separate agency - the European Personnel Selection Office (EPSO). In EPSO, the principles for recruitment policy are decided by a management board made up of representatives from the EU institutions, acting on proposals from the head of EPSO (European Communities 2002). The management board makes these decisions by qualified majority voting. The Commission has a much greater number of votes than the other institutions, reflecting its status as the principal recipient of recruits (with about 70 percent of total positions in the EU administration [Ban 2010, p. 14]).

The role of nationality in the European Commission has been a central topic in the public administration literature about the EU. This work has focused primarily on whether Commission officials hold supranational or inter-governmentalist views, that is, whether they adhere to the supranational values of the Commission or rather emphasize national interests (e.g. Hooghe 2005; Ellinas and Suleiman 2011; Egeberg 2012; Kassim et al. 2013). Prominent themes in this literature are the multiple role identities or allegiances of officials working for the European institutions and how the relative salience of these identities is affected by organizational and institutional features. Yet, while clearly relevant to discussions about representative bureaucracy, this literature has not addressed the multinational character of the EU administration as a question of representation. 
With the exception of Magali Gravier's recent work (Gravier 2008, 2013), no major studies have applied arguments about representative bureaucracy to the study of the Commission. This is surprising given the importance of geographical representation in the organization. In order to ensure fair representation of member states, the Commission has since the beginning needed to integrate staff from a number of different countries in its administrative apparatus (Page 1997; Egeberg 2006). This challenge has only grown with the gradual expansion of the European Union from its original six member states to its current 28 members (Christensen 2015).

Drawing on representative bureaucracy arguments, geographical representation in the European Commission can be seen to serve three principal functions. The first is the inclusion of national elites in the European institutions in order to create allegiance to the European project and shift identification to the European level (see Gravier 2013). The second is to ensure equal opportunities by giving citizens from new member states the possibility to participate in formulating EU policies and access to prestigious, secure and well-paid jobs in the EU institutions. Both elements may contribute positively towards the legitimacy and credibility of the EU. Enhancing legitimacy through bureaucratic representation may be particularly relevant given the power and autonomy of the executive bureaucracy in the EU (Egeberg 2006). The institutional design of the EU gives the Commission a near-monopoly on drafting and proposing legislation, whereas the mechanisms for parliamentary control are weak. It is often argued that a powerful bureaucracy insulated from the control of elected bodies has contributed to a 'democratic deficit' in the EU (Follesdal and Hix 2006). In this kind of political system, making the executive bureaucracy itself more representative may be an important way to increase legitimacy, as a supplement to political representation (cf. Groeneveld et al. 2016). A third function of geographical representation may be to increase the performance of the EU 
bureaucracy, for instance by allowing the administration to draw on the knowledge of citizens from new member states about the workings of national bureaucracies, legislation, languages, etc. It is worth noting that geographical representation in the Commission should be seen mainly as a form of passive representation (Gravier 2013). The staff regulations of the Commission explicitly state that officials shall act solely with the interests of the European Union in mind and prohibit officials from taking instruction from national governments.

In a couple of recent articles, Magali Gravier analyses the issue of geographical representation in the recruitment policies of the European Commission (Gravier 2008, 2013). She points to the special recruitment competitions for citizens from new member states as evidence for the role of representative bureaucracy in the EU. Under its regular staffing policies, the Commission is not allowed to take nationality into account when recruiting civil servants. Yet, in the special competitions organized during enlargement, nationality is an explicit selection criteria. These competitions thus follow a clear 'rationale of bureaucratic representation' (Gravier 2008, p. 1026). As Gravier herself points out, her analyses only constitute a first step in the examination of representative bureaucracy in the EU. While she traces the presence of representativeness criteria in the Commission's staff policies, she does not examine the implications of these representativeness criteria for other aspects of the Commission bureaucracy. Moreover, Gravier's analyses are based on very limited empirical data, consisting of a few policy documents and aggregate recruitment numbers. While building on Gravier's insights, this article takes the analysis of representative bureaucracy in the EU one step further. It not only develops a theoretical argument about the effects of geographical representation on the emphasis on specialist qualifications and skills in recruitment. It also tests this argument empirically using a new dataset of recruitment competitions for the European Commission, which allows for a systematic comparison of recruitment competitions where nationality was an explicit criterion 
(i.e. enlargement competitions) and competitions that did not take nationality into account (i.e. regular competitions). The theoretical argument and hypotheses are spelled out in the next section.

\section{Representation and specialist expertise in recruitment to the European Commission}

Our theoretical argument about the relationship between geographical representativeness and specialist expertise in recruitment centers on the mechanism of organizational socialization. Organizational socialization can be understood as 'the process by which an individual acquires the social knowledge and skills necessary to assume an organizational role' (Van Maanen and Schein 1977). This not only means acquiring the requisite skills for performing a job but also adopting the culture and unwritten norms of the organization. This process starts even before the individual enters the organization, as prospective employees learn about the organization and go through the selection procedure (Ban 2013, p. 99). The recruitment stage is therefore a crucial site for the socialization of new employees.

Arguments about organizational socialization are particularly relevant to the European Commission given the strong values and mission of the organization. Studies of the Commission frequently point to the existence of a common organizational culture built around the idea of defending the supranational, European interest (Ellinas and Suleiman 2012, p. 4, see also Egeberg 2006). To maintain such a culture in the face of changing organizational demographics, extensive organizational socialization is needed. This is illustrated in Carolyn Ban's book about the EU's Eastern enlargement in the 2000s, which uses organizational socialization as the primary theoretical lens for understanding how the Commission dealt with the organizational challenges related to enlargement (Ban 2013). 
Building on this, we argue that the recruitment of officials from a range of countries with different backgrounds, cultures and languages entails a greater need for socializing candidates into the practices and norms of the organization, and that this emphasis on socialization may imply less attention to the educational qualifications and specialist knowledge of candidates. Not only may concerns about socialization imply a greater focus on testing organization-specific knowledge and the ability to fit into the organization and less emphasis on assessing specialist qualifications. It may also imply hiring new officials at the lowest possible administrative level and in generalist fields in order to increase the organization's ability to socialize officials, which in turn implies a diminished emphasis on specialist qualifications and knowledge. As such, there may be a negative relationship between representativeness and the emphasis on specialist expertise in recruitment. The detailed mechanisms of this argument are specified in the theoretical expectations below.

Our first theoretical expectation is that the emphasis on geographical representativeness in recruitment is negatively related to the emphasis on educational qualifications. In recruitment competitions where geographical representativeness is a criterion, we expect there to be a greater concern about socializing a heterogeneous population of candidates. For the European Commission, a principal challenge in the enlargement of the EU has been the need to integrate a large and diverse group of staff into the existing organization and its culture (Ban 2013). Next to having the required technical skills, the ability to adapt to and function in a multinational work environment has thus become an explicit part of the recruitment design of the Commission. This, we argue, implies a greater focus on testing organization-specific knowledge, general skills such as language skills and the ability to fit into the organization and, as a result, less emphasis on assessing specialist qualifications and knowledge. We thus formulate hypotheses 1 and 2: 
Hypothesis 1: Geographical representativeness is negatively related to the emphasis on educational qualifications in a recruitment competition.

Hypothesis 2: Geographical representativeness is negatively related to the specialist content of tests that are used in a recruitment competition.

Apart from the direct negative relationships between geographical representativeness and specialist expertise, this relationship can be explained by the characteristics of the candidates to which the recruitment competition is tailored. A first such characteristic is the administrative grade for which officials are sought. Recruitment competitions for the European Commission can aim to recruit officials either for entry-level positions or for more senior administrative grades. The literature on socialization in the EU administration suggests that this decision is based in part on concerns about the ability to socialize officials. For instance, Suvarierol et al. (2013) argue that some EU agencies target inexperienced recruits that can more easily be socialized into certain organizational norms, while other agencies prefer hiring more experienced staff whose work experience can contribute to the agency's performance. Likewise, Ban argues that entrylevel officials are seen as more 'malleable' and are more quickly socialized into the norms of the European Commission (Ban 2013, p. 123). Given that socialization is a central concern in recruitment competitions for citizens from new member countries, we can expect the organization to hire new officials at the lowest possible level in order to increase its ability to socialize officials. Recruitment competitions for entry-level officials are in turn likely to put less emphasis on advanced educational qualifications and to focus less on specialist knowledge in tests. We therefore formulate hypotheses $3 \mathrm{a}$ and $3 \mathrm{~b}$ : 
Hypothesis 3a: The relationship between geographical representativeness and educational qualifications is (partly) mediated by administrative grade.

Hypothesis 3b: The relationship between geographical representativeness and specialist content of tests is (partly) mediated by administrative grade.

A second characteristic of the targeted recruits that can explain the negative relationship between geographical representativeness and specialist expertise is the field of the recruitment competition, which can generalist or specialist. A core tenet of the literature on professions is that specialists are committed to the norms and values of their specific professional group (Wilensky 1964; Mintzberg 1979). This means that they partly adhere to standards of behavior defined outside the bureaucratic agency in which they work (Wilson 1989, pp. 59-60). Generalists, by contrast, can be expected to be more loyal to the interests and values of the organization. Suvarierol and colleagues make a similar argument for the EU administration, pointing out that generalists typically are more loyal to EU's supranational norms, whereas specialist experts 'are primarily guided by the rules, criteria and standards of the professional group to which they belong' (Suvarierol et al. 2013, p. 920). In enlargement competitions, the socialization potential of candidates is arguably a central concern. We therefore expect that enlargement competitions to a larger extent will emphasize recruitment in generalist fields, since generalists are seen as more receptive to the organization's norms. Competitions in generalist fields can in turn be expected to pay less attention to formal educational qualifications and to put less emphasis on specialist content in recruitment tests. We thus propose hypotheses $4 \mathrm{a}$ and $4 \mathrm{~b}$. 
Hypothesis 4a: The relationship between geographical representativeness and educational qualifications is (partly) mediated by field of competition.

Hypothesis 4b: The relationship between geographical representativeness and specialist content of tests is (partly) mediated by field of competition.

These hypotheses give rise to the following conceptual model (see figure 1).

[Insert Figure 1 about here]

\section{RESEARCH DESIGN}

\section{Data collection}

We examine the issue of representativeness and knowledge in the EU bureaucracy through a quantitative analysis of recruitment competitions for the European Commission. The analysis is based on a dataset of competition notices, that is, public advertisements of upcoming recruitment competitions. Competition notices are legally binding documents that set out the modalities of the recruitment competitions, including the field of competition, the administrative grade of entry, the number of candidates to be recruited, eligibility and selection criteria, and the type of knowledge and skills tested.

The population studied comprises open competitions organized during the period 19582015 for entry to the European Commission and its forerunners as well as EPSO competitions intended for the European Commission. The analysis is restricted to competitions for recruitment of staff with policy tasks, which corresponds to the 'administrator' category of staff (i.e., 'AD' 
level staff, previously 'A' level staff). For detailed information on how the dataset was compiled, see the appendix.

Delimited in this way, the analysis encompasses 267 open competitions. After a listwise deletion of the competitions with missing values on the variables used in the analysis, the number of observations is 187 . Below we discuss the variables we use in the analysis.

\section{Measures}

The aim of the analysis is to examine the relationship between geographical representation and the emphasis on specialized expertise in recruitment. Following Max Weber, specialized expertise can be identified with the possession of advanced educational qualifications and specialized knowledge. In the analysis, we use two measures to capture this underlying concept. The first is whether the assessment of candidates in the recruitment competition takes into account educational qualifications (beyond the minimum education required to take part in a competition), rather than being based exclusively on tests. This is an indicator of the emphasis placed on formal education in recruitment: In competitions based in full or in part on educational qualifications, the candidate's level and type of education is considered (e.g., a $\mathrm{PhD}$ degree in economics may constitute an important advantage); in competitions based exclusively on tests, formal education beyond the minimum requirement is not considered. The first dependent variable educational qualifications is therefore a dummy variable that distinguishes between recruitment competitions that are based partly or fully on educational qualifications (1) and competitions that are based exclusively on tests (0). (See the appendix for further information about how the measures are constructed.)

The second measure of the emphasis on specialized expertise is to what extent recruitment tests assess specialist knowledge. The logic behind this measure is that even if recruitment 
competitions do not base assessment on formal educational qualifications, they may still target specialized expertise by placing great emphasis on specialist knowledge in the tests. To get at the underlying concept, we therefore need to take both these aspects into account. The second dependent variable specialist content of tests is therefore the percentage of the tests that is devoted to assessing specialist knowledge. To ensure comparability, the analysis of this dependent variable is confined to test-only competitions (Educational qualifications $=0$ ).

The main independent variable in the study is the presence of geographical representativeness criteria in the recruitment competition. This variable distinguishes between competitions where nationality was an explicit criterion, i.e., 'enlargement competitions' (geographical representativeness $=1$ ), and competitions that did not take nationality into account, i.e., 'regular competitions' (geographical representativeness $=0$ ). The former category includes all competitions that were open only to citizens from specific countries, whereas the latter category covers all competitions open to citizens from all member states.

The variable administrative grade is included as a possible mediator in the relationship between enlargement competitions and the educational qualifications and test content of recruitment competitions. According to our theoretical argument, the prior work experience of recruits is a central factor in determining how amenable officials are to organizational socialization, with entry-level officials without prior work experience being more malleable than those with more experience. In the analysis, we therefore distinguish between competitions for entry-level officials (for which no prior work experience is required) (administrative grade $=0$ ), and officials at higher grades (where prior work experience is required) (administrative grade $=$ 1).

The second mediating variable is field of competition. The variable field of competition consists of 19 categories, including 'general', 'public administration', 'law' and 'economics and 
statistics' (see appendix for full list). General competitions and competitions in general public administration are classified as 'generalist' (field of competition $=0$ ). Competitions in all other fields are classified as 'specialist' (field of competition =1). A single competition can recruit civil servants for multiple fields. Hence, the variable field is nested within competitions.

To account for confounding effects that may arise from differences in the number of candidates to be recruited in competitions, we control for the size of the competition. The variable size of competition is measured as the number of candidates sought in a competition.

Descriptive statistics for the variables are presented in table 1. The distribution of the variables over time are reported in the appendix.

[Insert Table 1 about here]

The correlations between the variables are displayed in table 2. The table shows that geographical representativeness is negatively correlated both with educational qualifications and specialist content of tests. Geographical representativeness is also negatively correlated with administrative grade and field of competition.

[Insert Table 2 about here]

\section{Analytical strategy}

From our conceptual model presented above, it follows that the effect of geographical representativeness on specialist qualifications and skills is mediated by administrative grade and field of competition. Figure 1 depicts the analytical model that results from our operationalization. We test the hypotheses by performing a mediation analysis according to the 
Baron and Kenny procedure (Baron and Kenny 1986). This analysis is explained in detail in the appendix.

\section{RESULTS}

In this section, mediation analyses are presented to test the theoretical expectations outlined in the study's conceptual model.

[Insert Table 3 about here]

\section{The indirect effect of geographical representativeness on educational qualifications}

Table 3 provides the estimates for the mediation analysis for educational qualifications. Consistent with our expectations, we find that - without modeling the effects of administrative grade and field of competition - geographical representativeness has a negative effect on educational qualifications $(b=-0.931 ; p<0.05)$. This means that enlargement competitions are significantly less likely than regular competitions to assess candidates fully or partly on the basis of educational qualifications (beyond the minimum education required to take part in the competition). Whereas 62 percent of regular competitions are based fully or partly on educational qualifications, this is the case for only 18 percent of enlargement competitions. Moreover, we find that geographical representativeness has a negative effect on administrative grade $(b=$ 1.950; $p<0.001)$, meaning that enlargement competitions are less likely than regular competitions to target higher-level officials. We also observe a negative effect of geographical representativeness on field of competition $(b=-1.062 ; p<0.001)$, which implies that enlargement competitions are more likely than regular competitions to be organized in generalist 
fields. In addition, administrative grade and field of competition both positively predict educational qualifications $(b=4.341 ; p<0.001$ and $b=0.610 ; p<0.05$, respectively). This implies that recruitment competitions for higher administrative grades and in specialist fields are more likely to include an assessment of educational qualifications. Finally, the significant effect of geographical representativeness (step 1) disappears when administrative grade and field are added to the model $(b=-0.234 ; p=0.656)$ (step 4). As expected, the control variable size of competition negatively predicts educational qualifications in all models, which means that competitions aimed at recruiting larger numbers of officials are less likely to consider educational qualifications. In all, the conditions for testing for mediation according to the Baron and Kenny procedure (1986) are met (see appendix).

Although Table 3 illustrates several direct relationships, it does not provide information about the indirect effect of geographical representativeness on educational qualifications. Bootstrapping $(\mathrm{N}=5000)$ is used to test whether the indirect effect of geographical representativeness on educational qualifications is significant. Table 4 presents the bootstrapped indirect effects of geographical representativeness on educational qualifications. It shows that both the indirect effect through administrative grade $(b=-0.345 ; p<0.001)$ and the indirect effect through field of competition $(b=-0.020 ; p<0.05)$ are negative and significant, and this is also the case for the total effect $(b=-0.407 ; p<0.05)$ and the total indirect effect $(b=-0.365 ; p<$ 0.001). The direct effect, however, is not statistically significant. The proportion of the total effect of geographical representativeness on educational qualifications that is mediated by administrative grade and field of competition is about 0.90 , which means that the relationship is almost fully mediated. All in all, we find support for our expectations that geographical representativeness has a negative effect on educational qualifications (hypothesis 1) and that this 
relationship is mediated by administrative grade (hypothesis 3a) and field of competition (hypothesis 4a).

[Insert Table 4 about here]

\section{The indirect effect of geographical representativeness on specialist content of tests}

Our second mediation model predicts specialist content of tests. The results are presented in Table 5. As expected, we find that geographical representativeness has a negative effect on specialist content of tests $(b=-9.586 ; p<0.01)$. In other words, the share of specialist knowledge assessed in recruitment tests is significantly lower in enlargement competitions than in regular competitions. Whereas the average share of tests devoted to specialist knowledge is 31 percent in regular competitions, it is merely 22 percent in enlargement competitions. As in the previous model, geographical representativeness has a significant, negative effect on administrative grade and field of competition $(b=2.003 ; p<0.001$ and $b=-0.790 ; p<0.01$, respectively). Field of competition, in turn, positively affects specialist content of tests $(b=7.687 ; p<0.001)$. However, the effect of administrative grade on specialist content of tests is not significant $(b=-2.367 ; p=$ 0. 351). By adding both administrative grade and field of competition to the model, the negative effect of enlargement competition becomes stronger instead of weaker $(b=-11.254 ; p<0.001)$. The size of the competition has no significant effect on specialist content of tests. In all, the conditions for testing for mediation are not met.

[Insert Table 5 about here] 
Because the effect of administrative grade on specialist content of tests is not significant, we test the mediating effect of field of competition separately (see table 6). Without administrative grade, the effect of field of competition on specialist content of tests is significant and positive $(b=$ 7.310; $p<0.001$ ). Moreover, the effect of geographical representativeness (step 1) decreases when field of competition is added to the model $(b=-0.234 ; p=0.656)$ (step 4). Hence, the effect of geographical representativeness could be partially mediated through field of competition. To test the indirect effect of geographical representativeness on specialist content of tests through field of competition, we perform bootstrapping $(\mathrm{N}=5000)$ (see table 7). We find that both the indirect and the direct effect of geographical representativeness are negative and significant $(b=-$ 0.037; $p<0.01$ and $b=-0.322 ; p<0.001$, respectively). The proportion of the total effect of geographical representativeness on specialist content of tests that is mediated through field of competition is about 0.10 . Hence, we find support for the negative effect of geographical representativeness on specialist content of tests (hypothesis 2) and the mediating effect of field of competition (hypothesis 4b). The data provide no evidence for the mediating effect of administrative grade (hypothesis $3 b$ ).

To assess the robustness of our findings, we also estimated all models with the year of the competition as an additional control variable, in order to control for any over-time variation driven by omitted variables. The results of the additional analyses are comparable to the results presented here (results of the extra analyses are not reported here but are available on request).

[Insert Table 6 about here]

[Insert Table 7 about here] 


\section{DISCUSSION AND CONCLUSION}

The analysis provides empirical evidence for a negative relationship between geographical representativeness and specialist expertise in the recruitment policies of the European Commission. We find a negative and significant relationship between the presence of representativeness criteria and two key measures of the emphasis on specialist knowledge in recruitment: the use of educational qualifications to assess candidates and the emphasis on specialist knowledge in recruitment tests. Moreover, we show that this relationship was mediated by the defined field of recruitment (for both measures) and by the administrative grade for which new entrants were sought (for the use of educational qualifications). In other words, enlargement competitions put less emphasis on specialist qualifications and knowledge, and were more frequently targeted at generalist fields and entry-level positions, than regular recruitment competitions. Thus, while geographical representation among Commission staff may have contributed positively to the legitimacy of the organization and to certain aspects of its performance, it entailed less emphasis on specialized expertise in the recruitment of staff.

The findings also provide tentative support for the causal mechanism we propose to explain this relationship, namely the greater perceived need of the organization to socialize officials from the new member states (cf. Ban 2013; Christensen 2015). The greater emphasis in enlargement competitions on recruitment for entry-level positions and in generalist fields is consistent with a concern with making new entrants fit the organizational mold. To be sure, we lack qualitative evidence to prove that socialization concerns determined the design of recruitment policies. Yet, we see it as plausible that the Commission actors in charge of recruitment policies - first DG Personnel and Administration and later the Commission representative on the EPSO Management Board - would be concerned about the issue. Also, we 
see it as plausible that Commission leaders made conscious, strategic decisions about how to deal with the recruitment challenges arising from major events such as EU enlargements - including what kind of skills and knowledge to ask of officials from new member states. For instance, Carolyn Ban shows that the Commission made extensive preparations for the selection and integration of new staff in relation to the Eastern enlargement in the 2000s (Ban 2013). More generally, the importance of socialization in the European institutions has been highlighted in a number of existing EU studies (e.g. Beyers 2010; Suvarierol et al. 2013).

There are of course other possible explanations for the lower emphasis on specialist qualifications in enlargement competitions. One alternative explanation is that more practical concerns related to selecting large numbers of new officials led to more generic recruitment tests. Yet, we address this possibility by controlling for the size of the recruitment competition in the analysis. While competition size is a significant predictor of the reliance on educational qualifications in recruitment, it does not cancel out the effect of geographical representation or the mediating variables. Another possibility is that recruiting officials from new member states in generic categories made it easier to fill open positions in the Commission. However, whereas this would be true for some positions, recruitment of candidates with generic skills would make it more difficult to fill posts requiring specific competences. Third, the lower emphasis on specialized expertise in enlargement competitions could be attributed to the anticipation of differences in the profile of applicants. For instance, the variety of educational systems in the new member states could have led the Commission to rely less on university degrees in recruitment. Yet, we would have expected this to be compensated by a greater emphasis on assessing specialist knowledge through tests. Instead, our analysis shows that enlargement competitions put less emphasis on specialist content in tests. In addition, some would argue that the diminished attention to specialist skills reflects broader trends in human resource management towards the 
assessment of general 'competences' rather than expert knowledge (cf. Lodge and Hood 2005). However, this cannot explain the lower emphasis on specialist knowledge during enlargement, since 'competence'-based selection procedures were introduced only in 2010, that is, after the completion of the special recruitment competitions related to Eastern enlargement (Ban 2010).

A final consideration concerns whether our findings are specific to particular rounds of European enlargement. Following our socialization argument, one could argue that the large differences between existing and new member states during Eastern enlargement would entail a relatively greater perceived need for socialization and, in turn, relatively less emphasis on specialized knowledge, as compared to previous rounds of enlargements. The limited number of observations in the population of recruitment competitions does not allow us to test for differences between the various enlargement rounds. However, the robustness check that we perform - controlling for year of competition - shows that the negative relationship between representativeness and specialist expertise is independent from the period in which the competition took place, which suggests that the relationship is not specific to Eastern enlargement.

It is important to emphasize that our findings only concern what qualifications and knowledge are asked for in recruitment competitions. The analysis does not allow us to say whether officials recruited based on geographical representativeness actually had lower educational qualifications or specialist knowledge than others. There are reasons why this may not be the case, such as the ability to tap into a broader pool of qualified candidates when expanding the geographical scope of recruitment and the greater attractiveness of the terms of employment in the Commission for citizens from new member states. While systematic analyses are missing, some studies of the EU's Eastern enlargement suggest that officials recruited from the new member states generally were well educated (Ban 2013, p. 106; Kassim et al. 2013). At 
the same time, the way an organization recruits its staff is bound to influence the role identification of officials (Ban 2010; Christensen 2015). As such, a selection procedure that emphasizes generalist skills over specialist qualifications and knowledge sends a clear signal to new entrants about the kind of competences that are valued by the organization and the kind of role officials are expected to play.

Based on this, the need to ensure fair national bureaucratic representation in an expanded European Union can be seen as one explanation for the increasingly generalist character of the European Commission. Several recent studies of the Commission paint a picture of an organization where generalist skills and the ability to deal with a broad range of policy issues is valued over advanced expertise in specific fields (Wille 2013; Suvarierol et al. 2013). Often, this trend is ascribed to the administrative reforms of the early 2000 s, which included requirements for regular staff rotation (Ban 2013, p. 94; Wille 2013, p. 129). Yet, our analysis suggests that this development may also be rooted in the successive rounds of EU enlargement, which have implied a greater emphasis on generalist skills (see also Christensen 2015). These findings also raise questions about the broader impact of geographical representation on the EU's administrative system.

Another contribution of this study is that it extends the debate about representative bureaucracy in international organizations (cf. Gravier 2008, 2013). Our argument addresses a key challenge faced by international organizations, namely how to ensure both fair national representation and specialized expertise in their administration. To be sure, the extent to which international administrations strive for geographical representativeness varies, depending on features such as the scope of the organization and its governance structures. The EU is a special case in this regard, given that it is a broad multi-purpose organization with a highly developed executive bureaucracy endowed with considerable political powers. Yet, other organizations, 
such as the United Nations, also have large permanent administrations and face strong expectations about fair representation. Moreover, the relationship between geographical representation and specialized expertise may vary across international organizations, depending on their recruitment system and the need to manufacture a common organizational culture. For instance, organizations where recruits are pre-socialized into a common professional culture may be less concerned about socializing new officials than the European Commission. A more farreaching application of arguments about representative bureaucracy would also investigate other forms of representation (gender, race or sexual orientation) in international bureaucracies, as well as the effects of representation on the effectiveness and legitimacy of these organizations (Groeneveld et al. 2016).

Even though the precise scope of the relationship between representation and specialist expertise needs to be explored further, the central argument of this article about the potential negative relationship between the two constitutes a novel contribution to the representative bureaucracy literature. While this literature so far has focused mainly on the positive effects of representation in public bureaucracies on legitimacy and organizational performance, this article suggests that there may be trade-offs between representation and other important concerns in public administration (Lim 2006; Kennedy 2014). Our argument about the implications of representation for specialized expertise in public organizations opens up a new front in this discussion. Given the importance of skills-based bureaucratic recruitment for the quality of government (Dahlström et al. 2012), the expertise of officials is an issue that needs to be taken seriously in the literature on representative bureaucracy. 


\section{ACKNOWLEDGEMENTS}

We would like to thank Sandra Groeneveld for inspiration and encouragement to write this article. We also thank Kenneth J. Meier, the participants at the workshop on representative bureaucracy at the 2016 Public Management Research Conference in Aarhus and three anonymous reviewers for providing us with valuable comments. 


\section{REFERENCES}

Andrews, R. and R. Ashworth. 2015. 'Representation and Inclusion in Public Organizations: Evidence from the U.K. Civil Service', Public Administration Review, 75, 2, 279-88.

Ban, C. 2010. 'Reforming the Staffing Process in the European Union Institutions: Moving the Sacred Cow out of the Road', International Review of Administrative Sciences, 76, 1, 524.

Ban, C. 2013. Management and Culture in an Enlarged European Commission: From Diversity to Unity? Basingstoke: Palgrave Macmillan.

Baron, R.M. and D.A. Kenny. 1986. 'The moderator-mediator variable distinction in social psychological research: Conceptual strategies and statistical considerations', Journal of Personality and Social Psychology, 51, 1173-82.

Beyers, J. 2010. 'Conceptual and methodological challenges in the study of European socialization', Journal of European Public Policy, 17, 6, 909-20.

Carnevale, D.G. 1990. 'Recruitment Strategies in the Federal Government: Missing Links and Representative Bureaucracy', Review of Public Personnel Administration 11, 1-2, 112-20.

Christensen, J. 2015. 'Recruitment and Expertise in the European Commission', West European Politics, 38, 3, 649-78.

Dahlström, C., V. Lapuente and J. Teorell. 2012. 'The Merit of Meritocratization: Politics, Bureaucracy, and the Institutional Deterrents of Corruption', Political Research Quarterly, 65, 3, 656-68.

Desbois, Y. 2003. 'Entretien avec Yves Desbois par Yves Conrad et Myriam Rancon'. Histoire interne de la Commission européenne 1958-1973. Florence: EU Historical Archives. 
Egeberg, M. 2006. 'Balancing Autonomy and Accountability: Enduring Tensions in the European Commission's Development', in M. Egeberg (ed.), Multilevel Union Administration: The Transformation of Executive Politics in Europe. Basingstoke: Palgrave Macmillan, pp. 31-50.

Egeberg, M. 2012. 'Experiments in supranational institution-building: The European Commission as a laboratory', Journal of European Public Policy, 19, 6, 939-50.

Ellinas, A. and E. Suleiman 2011. 'Supranationalism in a transnational bureaucracy: the case of the European Commission', Journal of Common Market Studies, 49, 923-47.

Esman, M.J. 1997. 'Public administration, ethnic conflict, and economic development', Public Administration Review, 57, 6, 527-33.

European Communities. 2002. 'Decision on the organisation and operation of the European Communities Personnel Selection Office'. 2002/261/EC, 25 July 2002.

Follesdal, A. and S. Hix. 2006. 'Why There is a Democratic Deficit in the EU: A Response to Majone and Moravcsik', Journal of Common Market Studies 44, 3, 533-62.

Gravier, M. 2008. 'The 2004 enlargement staff policy of the European Commission: The case for representative bureaucracy', Journal of Common Market Studies, 46, 1025-47.

Gravier, M. 2013. 'Challenging or Enhancing the EU's legitimacy? The Evolution of Representative Bureaucracy in the Commission's Staff Policies', Journal of Public Administration Research and Theory, 23, 4, 817-38.

Groeneveld, S. and S. Van de Walle. 2010. 'A contingency approach to representative bureaucracy: power, equal opportunities and diversity', International Review of Administrative Sciences, 76, 2, 239-58.

Groeneveld, S., K.J. Meier, E. Schröter and R. Andrews. 2016. 'Representative Bureaucracy and Public Service Performance: Where, Why, and How does Representativeness Work?' 
Paper presented at the Public Management Research Conference, Aarhus University, June 22-24, 2016.

Hood, C. and M. Lodge. 2006. The politics of public service bargains. Oxford: Oxford University Press.

Hooghe, L. 2005. 'Several roads lead to international norms, but few via international socialization: A case study of the European Commission', International Organization, 59, 861-98.

Kassim, H., J. Peterson, M.W. Bauer, S. Connolly, R. Dehousse, L. Hooghe and A. Thompson. 2013. The European Commission of the Twenty-First Century. Oxford: Oxford University Press.

Kennedy, B. 2014. 'Unraveling Representative Bureaucracy A Systematic Analysis of the Literature', Administration and Society, 46, 4, 395-421.

Kingsley, D.J. 1944. Representative bureaucracy: An interpretation of the British civil service. Yellow Springs, OH: Antioch Press.

Knill, C. and M.W. Bauer. 2016. 'Policy-making by international public administrations: concepts, causes and consequences', Journal of European Public Policy, 23, 7, 949-59.

Krislov, S. 1974. Representative bureaucracy. Englewood Cliffs, NJ: Prentice Hall.

Lipsky, M. 1980. Street-level bureaucracy: Dilemmas of the individual in public services. New York: Russell Sage Foundation.

Lodge, M. and C. Hood. 2005. 'Competency and Higher Civil Servants', Public Administration, $83,4,779-87$.

Meier, K.J. and J. Bohte. 2001. 'Structure and discretion: Missing links in representative bureaucracy', Journal of Public Administration Research and Theory, 11, 4, 455-70. 
Meier, K.J. and D.P. Hawes. 2009. 'Ethnic Conflict in France A Case for Representative Bureaucracy?' The American Review of Public Administration, 39, 3, 269-85.

Mintzberg, H. 1979. The Structuring of Organizations. New Jersey: Prentice Hall.

Mosher, F.C. 1968. Democracy and the Public Service. New York: Oxford University Press.

Page, E.C. 1997. People Who Run Europe. Oxford: Oxford University Press.

Pyburn, K.M., R.E. Ployhart and D.A. Kravitz. 2008. 'The diversity-validity dilemma: Overview and legal context', Personnel Psychology, 61, 143-51.

Suvarierol, S., M. Busuioc and M. Groenleer. 2013. 'Working for Europe? Socialization in the European Commission and Agencies of the European Union', Public Administration, 91, 4, 908-27.

Tilly, C. 1975. The formation of national states in Western Europe. Princeton, NJ: Princeton University Press.

Van Maanen, J.E. and E.H. Schein. 1977. Towards a theory of organizational socialization. Working papers from MIT Sloan School of Management, no. 960-77.

Weber, M. 1947. The Theory of Social and Economic Organization. Edited by T. Parsons. New York: Oxford University Press.

Weber, M. 1978. From Max Weber: Essays in Sociology. Edited by H.H. Gerth and C. Wright Mills. New York: Galaxy Books.

Wilensky, H. 1964. 'The Professionalization of Everyone?', American Journal of Sociology, 70, 2, 137-58.

Wille, A. 2013. The Normalization of the European Commission: Politics and Bureaucracy in the EU Executive. Oxford: Oxford University Press.

Wilson, J.Q. 1989. Bureaucracy: What Government Agencies Do and Why They Do It. New York: Basic Books. 


\section{TABLES AND FIGURES}

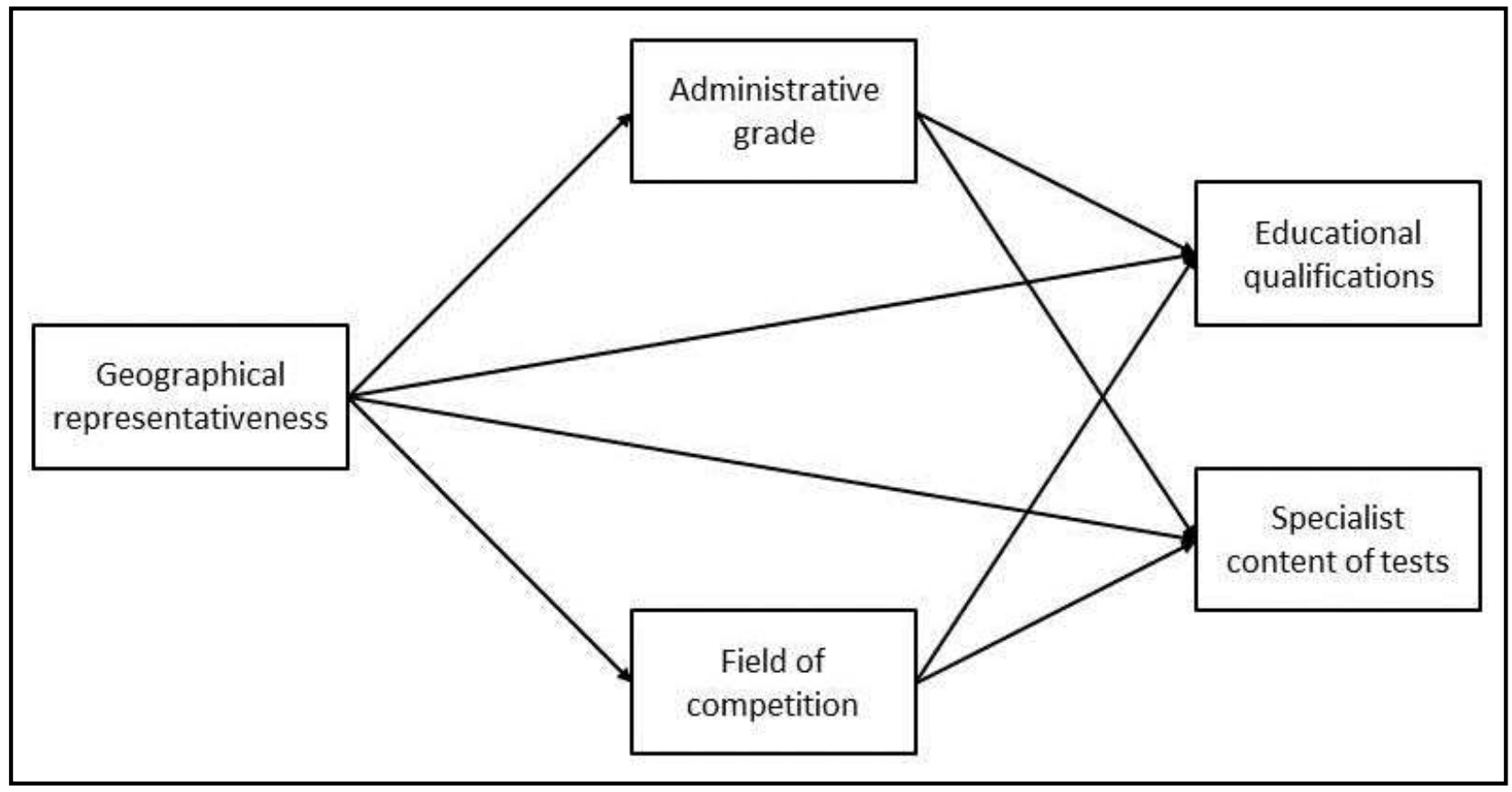

Figure 1 Conceptual Framework 
Table 1. Descriptive statistics for all variables in the analysis

\begin{tabular}{|c|c|c|c|c|c|}
\hline & $\mathrm{N}$ & Mean & Std. Dev. & Min & Max \\
\hline Educational qualifications (fully or partly based on educational qualifications $=1$ ) & 187 & .294 & .457 & 0 & 1 \\
\hline Specialist content of tests ${ }^{\dagger}$ & 130 & 26.523 & 14.000 & 0 & 66.5 \\
\hline Geographical representativeness (enlargement competitions $=1$ ) & 187 & .385 & .488 & 0 & 1 \\
\hline Administrative grade (officials at high grades $=1$ ) & 187 & .658 & .476 & 0 & 1 \\
\hline Field of competition $($ specialist $=1$ ) & 413 & .826 & .380 & 0 & 1 \\
\hline Size of competition & 187 & 79.594 & 83.582 & 2 & 475 \\
\hline
\end{tabular}

Note ${ }^{\dagger}$ Specialist content of tests if educational qualifications $=0$.

Table 2. Correlations for all variables in the analysis

$\begin{array}{llllll}(1) & (2) & (3) & (4) & (5) & (6)\end{array}$

\begin{tabular}{|c|c|c|c|c|c|c|c|}
\hline (1) & Educational qualifications (fully or partly based on educational qualifications $=1$ ) & 1.000 & & & & & \\
\hline (2) & Specialist content of tests ${ }^{\dagger}$ & . & 1.000 & & & & \\
\hline (3) & Geographical representativeness (enlargement competitions $=1$ ) & $-.421 *$ & $-.319 *$ & 1.000 & & & \\
\hline (4) & Administrative grade (officials at high grades $=1$ ) & $.830 *$ & .106 & $-.571 *$ & 1.000 & & \\
\hline (5) & Field of competition $($ specialist $=1)$ & .288 & $.219 *$ & $-.325^{*}$ & $.323 *$ & 1.000 & \\
\hline$(6)$ & Size of competition & $-.350 *$ & .020 & -.073 & $-.249 *$ & -.058 & 1.000 \\
\hline
\end{tabular}

Note. Tetrachoric correlations for dichotomous variables; ${ }^{\dagger}$ Specialist content of tests if educational qualifications $=0 ; * \mathrm{p}<0.05$ 
Table 3. Mediation analysis for educational qualifications; logistic regression

\begin{tabular}{|c|c|c|c|c|c|}
\hline & $\begin{array}{l}\text { Educational } \\
\text { qualifications } \\
\text { (step 1) }\end{array}$ & $\begin{array}{l}\text { Administrative } \\
\text { grade } \\
\text { (step 2) }\end{array}$ & $\begin{array}{l}\text { Field of } \\
\text { competition } \\
\text { (step 2) }\end{array}$ & $\begin{array}{l}\text { Educational } \\
\text { qualifications } \\
\text { (step 3) }\end{array}$ & $\begin{array}{l}\text { Educational } \\
\text { qualifications } \\
\text { (step 4) }\end{array}$ \\
\hline \multirow{3}{*}{ Geographical representativeness (enlargement competitions $=1$ ) } & $\mathrm{b} / \mathrm{se}$ & $\mathrm{b} / \mathrm{se}$ & $\mathrm{b} / \mathrm{se}$ & $\mathrm{b} / \mathrm{se}$ & $\mathrm{b} / \mathrm{se}$ \\
\hline & $-0.931 *$ & $-1.950 * * *$ & $-1.062 * * *$ & & -0.234 \\
\hline & $(0.460)$ & $(0.424)$ & $(0.224)$ & & $(0.525)$ \\
\hline \multirow[t]{2}{*}{ Administrative grade (officials at high grades $=1$ ) } & & & & $4.341 * * *$ & $4.256^{* * *}$ \\
\hline & & & & $(1.048)$ & $(1.109)$ \\
\hline \multirow{2}{*}{ Field of competition $($ specialist $=1$ ) } & & & & $0.610^{*}$ & $0.530^{*}$ \\
\hline & & & & $(0.287)$ & $(0.261)$ \\
\hline \multirow[t]{2}{*}{ Size of competition } & $-0.018 * * *$ & $-0.012 * * *$ & $-0.002 * *$ & $-0.013 * *$ & $-0.013 * *$ \\
\hline & $(0.005)$ & $(0.003)$ & $(0.001)$ & $(0.005)$ & $(0.005)$ \\
\hline \multirow{2}{*}{ Constant } & $0.735^{*}$ & $2.871 * * *$ & $2.440 * * *$ & $-4.392 * * *$ & $-4.100 * *$ \\
\hline & $(0.339)$ & $(0.414)$ & $(0.234)$ & $(0.457)$ & $(0.447)$ \\
\hline chi2 & 14.778 & 31.119 & 25.342 & 28.362 & 34.142 \\
\hline Df & 2 & 2 & 2 & 3 & 4 \\
\hline Pseudo R2 & .152 & .188 & .041 & .296 & .298 \\
\hline N Competitions & 187 & 187 & 187 & 187 & 187 \\
\hline N Fields & 413 & 413 & 413 & 413 & 413 \\
\hline
\end{tabular}

$+\mathrm{p}<0.10, * \mathrm{p}<0.05, * * \mathrm{p}<0.01, * * * \mathrm{p}<0.001$ 
Table 4. Bootstrapping indirect effects of geographical representativeness on educational qualifications via administrative grade and field of competition

\begin{tabular}{|c|c|c|c|c|c|c|c|}
\hline & $\begin{array}{l}\text { Observed } \\
\text { Coef. }\end{array}$ & $\begin{array}{l}\text { Bootstrap } \\
\text { Err. }\end{array}$ & Std. & $\mathrm{Z}$ & $\mathrm{P}>\mathrm{Z}$ & \multicolumn{2}{|c|}{$\begin{array}{l}\text { Normal-based }[90 \% \\
\text { Conf. Interval] }\end{array}$} \\
\hline $\begin{array}{l}\text { Indirect effect through } \\
\text { administrative grade }\end{array}$ & -.345 & .065 & & -5.29 & .000 & -.452 & -.238 \\
\hline $\begin{array}{l}\text { Indirect effect through field of } \\
\text { competition }\end{array}$ & -.020 & .010 & & -1.99 & .046 & -.037 & -.004 \\
\hline Total indirect effect & -.365 & .068 & & -5.40 & .000 & -.476 & -.254 \\
\hline Direct effect & -.042 & .103 & & -.41 & .684 & -.211 & .127 \\
\hline Total effect & -.407 & .105 & & -3.88 & .000 & -.579 & -.234 \\
\hline
\end{tabular}


Table 5. Mediation analysis for specialist content of tests; logistic and OLS regression

\begin{tabular}{|c|c|c|c|c|c|}
\hline & $\begin{array}{l}\text { Specialist content } \\
\text { of tests } \\
\text { (step 1) }\end{array}$ & $\begin{array}{l}\text { Administrative } \\
\text { grade } \\
\text { (step 2) }\end{array}$ & $\begin{array}{l}\text { Field of } \\
\text { competition } \\
\text { (step 2) }\end{array}$ & $\begin{array}{l}\text { Specialist content } \\
\text { of tests } \\
\text { (step 3) }\end{array}$ & $\begin{array}{l}\text { Specialist content } \\
\text { of tests } \\
\text { (step 4) }\end{array}$ \\
\hline & $\mathrm{b} / \mathrm{se}$ & $\mathrm{b} / \mathrm{se}$ & $\mathrm{b} / \mathrm{se}$ & $\mathrm{b} / \mathrm{se}$ & $\mathrm{b} / \mathrm{se}$ \\
\hline \multirow{2}{*}{ Geographical representativeness (enlargement competitions $=1$ ) } & $-9.586 * *$ & $-2.003 * * *$ & $-.790 * *$ & & $-11.254 * * *$ \\
\hline & (3.029) & $(.472)$ & $(.242)$ & & $(3.260)$ \\
\hline \multirow[t]{2}{*}{ Administrative grade (officials at high grades $=1$ ) } & & & & -2.367 & $-6.361 *$ \\
\hline & & & & $(2.530)$ & $(2.477)$ \\
\hline \multirow[t]{2}{*}{ Field of competition ( specialist $=1$ ) } & & & & $7.687 * * *$ & $6.423 * * *$ \\
\hline & & & & $(1.629)$ & (1.769) \\
\hline \multirow[t]{2}{*}{ Size of competition } & -.013 & $-.010 * * *$ & -.001 & -.003 & -.022 \\
\hline & $(.014)$ & $(.003)$ & $(.001)$ & $(.009)$ & $(.014)$ \\
\hline \multirow[t]{2}{*}{ Constant } & $32.190 * * *$ & $2.195^{* * *}$ & $-1.970 * * *$ & $20.580 * * *$ & $32.257 * * *$ \\
\hline & $(3.225)$ & $(.481)$ & $(.258)$ & $(2.815)$ & (3.338) \\
\hline Pseudo R2 & & .155 & .021 & & \\
\hline $\mathrm{R} 2$ & .113 & & & .055 & .187 \\
\hline Adjusted R2 & .107 & & & .045 & .176 \\
\hline N Competitions & 130 & 130 & 130 & 130 & 130 \\
\hline N Fields & 293 & 293 & 293 & 293 & 293 \\
\hline
\end{tabular}

$+\mathrm{p}<0.10, * \mathrm{p}<0.05, * * \mathrm{p}<0.01, * * * \mathrm{p}<0.001$ 
Table 6. Mediation analysis for specialist content of tests; logistic and OLS regression

\begin{tabular}{|c|c|c|c|c|}
\hline & $\begin{array}{l}\text { Specialist content } \\
\text { of tests } \\
\text { (step 1) }\end{array}$ & $\begin{array}{l}\text { Field of } \\
\text { competition } \\
\text { (step 2) }\end{array}$ & $\begin{array}{l}\text { Specialist content } \\
\text { of tests } \\
\text { (step 3) }\end{array}$ & $\begin{array}{l}\text { Specialist content } \\
\text { of tests } \\
\text { (step 4) }\end{array}$ \\
\hline & $\mathrm{b} / \mathrm{se}$ & $\mathrm{b} / \mathrm{se}$ & $\mathrm{b} / \mathrm{se}$ & $\mathrm{b} / \mathrm{se}$ \\
\hline \multirow{2}{*}{$\begin{array}{l}\text { Geographical representativeness } \\
(\text { enlargement competitions }=1 \text { ) }\end{array}$} & $-9.586 * *$ & $-.790 * *$ & & $-8.869 * *$ \\
\hline & $(3.029)$ & $(.242)$ & & (3.018) \\
\hline \multirow[t]{2}{*}{ Field of competition ( specialist $=1$ ) } & & & $7.310 * * *$ & $5.815 * * *$ \\
\hline & & & $(1.692)$ & $(1.688)$ \\
\hline \multirow[t]{2}{*}{ Size of competition } & -.013 & -.001 & -.000 & -.012 \\
\hline & $(.014)$ & $(.001)$ & $(.010)$ & $(.014)$ \\
\hline \multirow[t]{2}{*}{ Constant } & $32.190 * * *$ & $1.970 * * *$ & $19.403 * * *$ & $27.038 * * *$ \\
\hline & $(3.225)$ & $(.258)$ & $(2.145)$ & $(3.597)$ \\
\hline Pseudo R2 & & .021 & & \\
\hline $\mathrm{R} 2$ & .113 & & .048 & .143 \\
\hline Adjusted R2 & .107 & & .041 & .134 \\
\hline N Competitions & 130 & 130 & 130 & 130 \\
\hline N Fields & 293 & 293 & 293 & 293 \\
\hline
\end{tabular}

$+\mathrm{p}<0.10, * \mathrm{p}<0.05, * * \mathrm{p}<0.01, * * * \mathrm{p}<0.001$

Table 7. Bootstrapping indirect effects of geographical representativeness on specialist content of tests via field of competition

\begin{tabular}{lllllll}
\hline & $\begin{array}{l}\text { Observed } \\
\text { Coef. }\end{array}$ & $\begin{array}{l}\text { Bootstrap Std. } \\
\text { Err. }\end{array}$ & $\mathrm{z}$ & $\mathrm{P}>\mathrm{z}$ & \multicolumn{2}{l}{$\begin{array}{l}\text { Normal-based [90\% } \\
\text { Conf. Interval] }\end{array}$} \\
\hline $\begin{array}{l}\text { Indirect effect through field of } \\
\text { competition }\end{array}$ & -.037 & .014 & -2.67 & .008 & -.059 & -.014 \\
Direct effect & & & & & & \\
Total effect & -.322 & .088 & -3.65 & .000 & -.467 & -.177 \\
\hline
\end{tabular}

